\title{
EFFECT OF COMPOSTING PLANT MATERIAL WITH COPOLYESTER ON QUALITY OF ORGANIC MATTER
}

\author{
WPLYW PROCESU KOMPOSTOWANIA MATERIAŁU ROŚLINNEGO \\ Z KOPOLIESTREM NA JAKOŚĆ MATERII ORGANICZNEJ
}

\begin{abstract}
The problem of incorporating plastics into the environment will be aggravating, both regarding its scale and kind of these materials. Investigations were carried out using aliphatic-aromatic copolyester poly (succinate-co-glutarate-co-adipate-co-terephthalate 1,4-butylene) with addition of fatty acid dimers. The work aimed to determine the effect of composting the copolyester with plant biomass on changes of fractional composition of humus substances and their stability. Copolyester was supplemented to the biomass in the form of a nonwoven fabric in two doses. It constituted 8 and $16 \%$ of the dry mass of the composted substrates. The composting process was run within two ranges of ambient temperature $25-30^{\circ} \mathrm{C}$ and $40-45^{\circ} \mathrm{C}$. After the completion of this process, the degree of material maturing was assessed using manometric methods and the carbon content was analysed in the individual organic matter fractions. On the basis of cumulated respiratory activity AT4 a lack of composted material activity was revealed in the higher temperatures of the process. However, in the objects where copolyester was transformed in the lower temperatures this activity was considerably diversified. Adding copolyester to the composted biomass led to a diversification of the $C_{h a}: C_{f a}$ ratio. The values of $C_{h a}: C_{f a}$ ratio most approximating 1.5, ie the value regarded as optimal, were registered in the object, where copolyester supplement constituted $16 \%$ and the plant biomass was maintained within the $40-45^{\circ} \mathrm{C}$ temperature range.
\end{abstract}

Keywords: compost, copolyester, carbon fractions, respiratory activity

\section{Introduction}

Humus transformations in soil, both quantitative and qualitative, awaken an interest of science and practice [1]. It is due to the role of humus in the environment, its still not fully determined composition and multidirectional changes which it undergoes in time. The ambiguity of humus composition is connected with various sources of the substrates which constitute it. Despite similarities of humus compounds regarding their composition, it still remains diversified. It results from diversification of the material which was subjected to humification process and from different conditions and the rate of the formation of humus compounds. The process of organic matter humification in soil is influenced by many

\footnotetext{
${ }^{1}$ Department of Agricultural and Environmental Chemistry, University of Agriculture in Krakow, al. A. Mickiewicza 21, 31-120 Kraków, Poland

${ }^{2}$ Institute of Polymers and Chemical Fibres, ul. M. Słodowskiej-Curie 19/27, 90-570 Łódź, Poland

*Corresponding author: rrkopec@cyf-kr.edu.pl
} 
factors, among others microbial activity, including the kind of microorganisms and balanced content of nutrients, air and water conditions, the temperature and $\mathrm{pH}$. Additionally, the qualitative and quantitative transformations of organic matter depend on the balance between humification and mineralization processes.

The issues of humus gain particular importance in the case of substances which have not been incorporated into the soil so far. For over 20 years, while intensively looking for technical and technological solutions, the industry has been introducing products for which composting process, their disintegration and biodegradation are meant as the final solution [2]. Considering the diversity of materials suggested by the industry the standards allowing these products to be used in the environment should be taken into consideration. This particularly applies to so called Agricultural Plastic Waste (APW) [3]. Processes of mineralisation and humification occurring during composting are intensified and under better control than under the natural conditions. However, not always the degree of compost maturity and its stability, ie the effect of transformation process will satisfy a potential user. The quality of compost to a great extent depends on the composting technology, but the basic factor is the kind of composted substrates, including polymer materials incorporated into the process of biological transformations [4-6] or additives modifying these materials, eg pigments [7]. According to Chlopek et al [8] determining the structure of the material subjected to biodegradation is important and necessary at the stage of determining the parameters of the process.

Among a number of plastics undergoing biological transformation, aliphatic-aromatic copolyesters (AAC) are interesting due to economic reasons, but also cause anxiety [9]. Because of a complicated AAC structure and the presence of aromatic groups, this kind of material may not undergo total mineralisation whereas its disintegration and degradation products may constitute durable environmental pollution. It was confirmed, that biological transformation depends on the share of ethylene teraphtalene in their composition, and that at high ambient temperatures the degree of hydrolysis and microbial activity of the transformation process increases [5, 6]. It is caused by an easy access of enzymes and water to ester bonds, when these bonds are more apart. The degradation rate decreases with increasing molar mass of copolyesters. Materials revealing good mechanical properties undergo a slower degradation, because they contain a higher number of aromatic units.

The work aimed to determine the effect of the process of polyester composting with plant biomass on the changes of organic matter fractional composition and the degree of stability of the formed product.

\section{Material and methods}

\section{The scheme and conditions of the conducted experiment}

The nonwoven fabric used in the research was manufactured by the direct spun bonded method from a biodegradable aliphatic-aromatic copolyester poly(succinate-co-glutarateco-adipate-co-terephthalate 1,4-butylene) with the addition of fatty acid dimers. The polymer produced of petrochemical raw materials during a polycondensation process contained a modifier originating from the biomass products. The polymer synthesis was undertaken using $57 \%$ of aliphatic components and $6 \%$ of components from biomass - fatty acids dimers. Fatty acid dimers were obtained from the products of enzymatic transesterification of plant oils. The polymer and nonwoven fabric of this polymer were manufactured on large laboratory scale at the Institute of Polymers and Chemical Fibres in 
Lodz (Poland). The nonwoven fabric characteristics were presented in Figure 1 and Table 1.

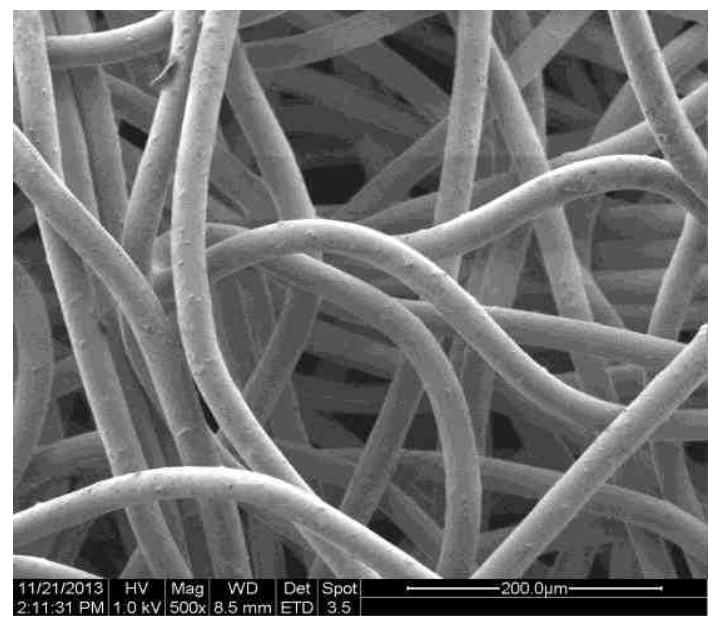

Fig. 1. SEM of nonwoven of aliphatic-aromatic polymers with modifier of biomass

Physico-chemical properties of nonwoven of aliphatic-aromatic polymers with modifier of biomass

\begin{tabular}{|c|c|c|}
\hline Property & Unit & Value \\
\hline Nonwoven thickness & {$[\mathrm{mm}]$} & 0.41 \\
\hline Surface mass & {$\left[\mathrm{g} \cdot \mathrm{m}^{-2}\right]$} & 81.8 \\
\hline Melting temperature & {$\left[{ }^{\circ} \mathrm{C}\right]$} & $109-114$ \\
\hline Glass transition temperature & {$\left[{ }^{\circ} \mathrm{C}\right]$} & $\sim-30$ \\
\hline Breaking strength in a longitudinal direction & {$[\mathrm{N}]$} & 4.46 \\
\hline Elongation at break in a longitudinal direction & {$[\%]$} & 60.1 \\
\hline Specific strength in a longitudinal direction & {$[\mathrm{MPa}]$} & 0.22 \\
\hline Breaking strength in a transverse direction & {$[\mathrm{N}]$} & 3.54 \\
\hline Elongation at break in a transverse direction & {$[\%]$} & 88.6 \\
\hline Specific strength in a transverse direction & {$[\mathrm{MPa}]$} & 0.17 \\
\hline Tear strength in a longitudinal direction & {$[\mathrm{N}]$} & 4.7 \\
\hline Tear strength in a transverse direction & {$[\mathrm{N}]$} & 4.9 \\
\hline Mean value of fibre diameter & {$[\mu \mathrm{m}]$} & 24.5 \\
\hline $\begin{array}{c}\text { Change of nonwoven fabric dimensions under the influence of hot } \\
\text { water } 80^{\circ} \mathrm{C} \text { in a longitudinal direction }\end{array}$ & {$[\%]$} & 17.1 \\
\hline $\begin{array}{c}\text { Change of nonwoven fabric dimensions under the influence of hot } \\
\text { water } 80^{\circ} \mathrm{C} \text { in a transverse direction }\end{array}$ & {$[\%]$} & 7 \\
\hline
\end{tabular}

The laboratory experiment conducted in 2014 involved nonwoven fabric composting with a mixture of wheat straw chaff, rapeseed straw and waste pea seeds in the proportions of 1:1:0.5 (the contents of substrate dry matter were respectively: $90.5 ; 88.5$ and $92.8 \%$ ). The aim of the experiment was to determine the optimal C:N ratio. The mixture of plant materials was moistened (to $60 \%$ of water content) and left for 24 hours. Composting was run in reactors holding $25 \mathrm{dm}^{3}$ of material, with a double perforated bottom allowing for even supply of pumped air and disposal of the effluent forming during the process. The aeration was performed by means of compressors, once a day at the flow of 10 litres of 
air/minute for an hour. Additionally, after four weeks, the mass in the reactors was aerated in weekly cycles and hand mixed, which also affected a better homogenisation of the composted mass. Composting was conducted within two ranges of the reactors ambient temperature. The first range was from $25-30^{\circ} \mathrm{C}$, the second $40-45^{\circ} \mathrm{C}$. A heating device switched itself on below the range of the composters' ambient temperature and then switched itself off when the upper limit was reached. After 50 days the temperature was progressively lowered to the level of $20-25^{\circ} \mathrm{C}$. In the first case, the change was made once; in the second, the temperature was lowered four times $5^{\circ} \mathrm{C}$ per week.

Three objects were maintained within each range of composting temperatures: K0 a mixture of plant materials without nonwoven fabric supplement, K8 - a mixture of plant materials with a $8 \%$ admixture of nonwoven fabric and K16 - a mixture of plant materials with a $16 \%$ nonwoven fabric supplement. The nonwoven fabric added to the plant materials mixture had the same dimensions: $10 \mathrm{~cm} \mathrm{x} 10 \mathrm{~cm}$ (Fig. 2). The composting process was conducted in two replications for each treatment and was completed after 90 days. The temperature of composted material was registered during the process in each reactor every 10 minutes (13 thousand measurements). Temperature recorders (DK-171) were validated prior to the experiment and showed a deviation of $\pm 0.4^{\circ} \mathrm{C}$.

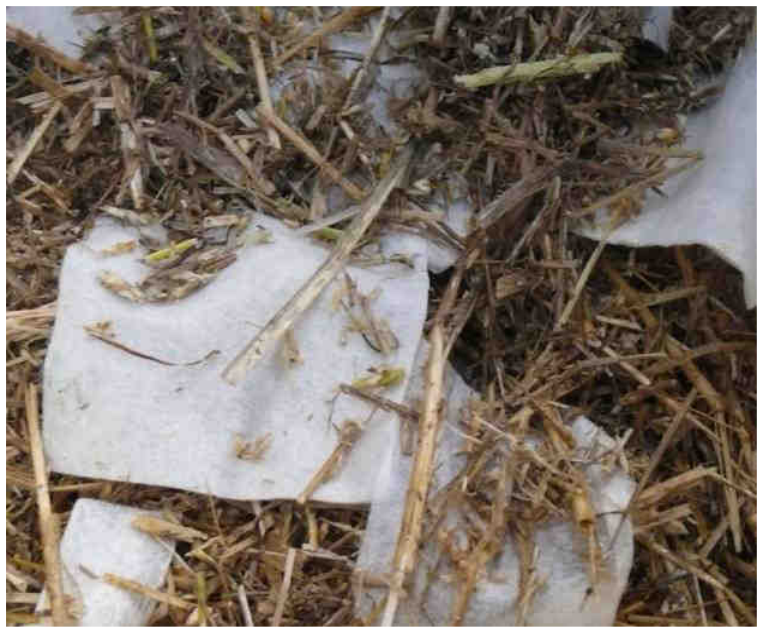

Fig. 2. A mixture of composted biomass and nonwoven fabric

\section{Analysis of biological activity}

After comliting the experiment respiratory activity of the composted materials was assessed taking into consideration the ISO norm 14855-1:2005. The manometric method was used and measurements were conducted with the help of the Oxi-Top apparatus (Fig. 3). The remaining mass was calculated on the basis of dry mass content assessed through water losses at $105^{\circ} \mathrm{C}$.

Manometric measurement comprised a change of pressure in a closed vessel (Fig. 3). The pressure changes are proportional to oxygen consumption by microorganisms in a sample [11]. The time of activity measurement was 5 days (1 day of stabilising the conditions and 4 days for actual measurements of respiratory activity) and changes of 
pressure were registered automatically every 30 minutes. The evolved $\mathrm{CO}_{2}$ was absorbed by $1 \mathrm{~mol} \cdot \mathrm{dm}^{-3} \mathrm{NaOH}$ solution.
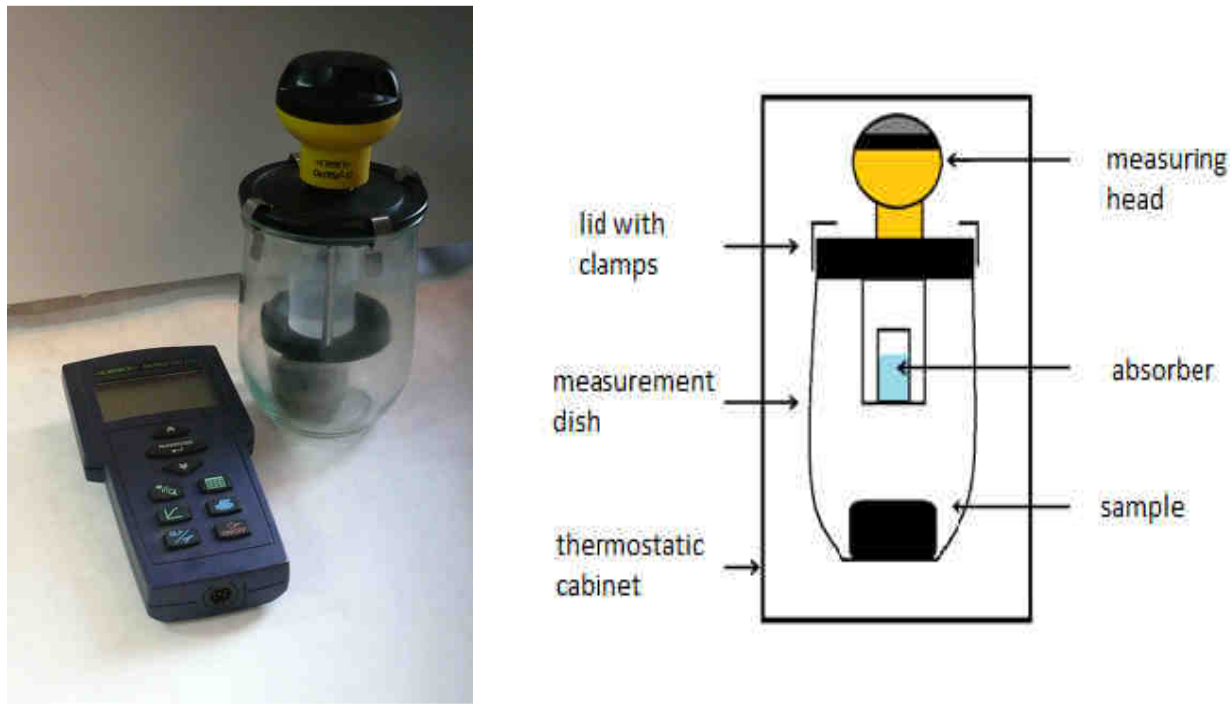

Fig. 3. Photograph and construction scheme of measuring vessel for measuring oxygen demand

The applied system consisted of $2.5 \mathrm{dm}^{3}$ measurement bottles and auxiliary equipment. For the period of assessment, bottles were placed in a thermostatic cabinet, ensuring the constant temperature of $25.0^{\circ} \mathrm{C}\left( \pm 0.1^{\circ} \mathrm{C}\right)$. The data from the measurement were sent to a controller through an infrared interface and then to a computer by means of Achat OC programme. Cumulated value of the material biological activity AT4 (96 hours) was expressed in $\mathrm{O}_{2} \cdot \mathrm{g}^{-1} \mathrm{~d} . \mathrm{m}$. of the composted material. It was calculated according to the following formula:

$$
B A=\left(M O_{2} \cdot V_{f r} \cdot|\Delta p|\right) /\left(R \cdot T \cdot m_{B t}\right)
$$

where: $B A$ - biological activity, $M O_{2}$ - oxygen molecular weight $(31998 \mathrm{mg} / \mathrm{mol}), R$ - the gas constant $\left[\left(83.14 \mathrm{dm}^{3} \cdot \mathrm{hPa}\right) /(\mathrm{K} \cdot \mathrm{mol})\right], T$ - temperature $[\mathrm{K}], m_{B t}$ - soil dry weight $[\mathrm{kg}]$, $|\Delta p|$ - change of pressure [hPa], $V_{f r}$ - free gas volume calculated in the following way:

$$
V_{f r}=V_{g e s}-V_{A M}-V_{B f}
$$

where: $V_{\text {ges }}$ - total volume of sample bottle, $V_{A M}$ - volume of the absorber and internal auxiliary equipment, $V_{B f}$ - volume of moist soil.

\section{Analysis of humic compounds fractions}

When the composting process was completed, an analysis of organic carbon content was conducted using the redox titration method. Extraction of humic acids ( 24 hours) was conducted using the Schnitzer's method [12] with a $0.5 \mathrm{~mol} \cdot \mathrm{dm}^{-3} \mathrm{NaOH}$ solution (as a result $\mathrm{C}$ of the extract was determined). Humic acid carbon $\left(C_{h a}\right)$ was separated from the extract by the extract acidification with sulphuric acid to $\mathrm{pH} \sim 2$. Carbon content was assessed in both fractions using redox titration method. The content of fulvic acid carbon $\left(C_{f a}\right)$ and non-hydrolysing carbon $\left(C_{n h}\right)$ was calculated as follows: 


$$
\begin{gathered}
C_{f a}=\text { extract } \mathrm{C}-C_{h a} \\
C_{n h}=\text { organic } \mathrm{C}-\text { extract } \mathrm{C}
\end{gathered}
$$

Optic properties within the UV-VIS range for $0.02 \%$ solutions of humic acids in $0.1 \mathrm{~mol} \cdot \mathrm{dm}^{-3} \mathrm{NaOH}$ were determined on Beckman DU640 spectrophotometer after initial samples dissolving in $0.1 \mathrm{~mol} \cdot \mathrm{dm}^{-3} \mathrm{NaOH}(1: 5)$. On the basis of absorbance values determined at $465 \mathrm{~nm}$ (E4) and $665 \mathrm{~nm}$ (E6) wavelengths, the values of E4:E6 coefficient were calculated.

The reported results constitute the arithmetic mean of 4 replications. Standard deviation $(S D)$ was computed for the values of arithmetic means listed in Tables 2 and 4.

\section{Results and discussion}

\section{Temperature}

The range of temperatures within the composted mass (Fig. 4) did not differ from the ambient temperature, except for the object K16 with the $16 \%$ share of nonwoven fabric maintained at the ambient temperature of $25-30^{\circ} \mathrm{C}$. Mean values of the temperature (Table 2 ) indicate, that until the $50^{\text {th }}$ day, the temperature in the composted biomass of this object remained by $6.5^{\circ} \mathrm{C}$ higher as compared with the control at the same temperature range.

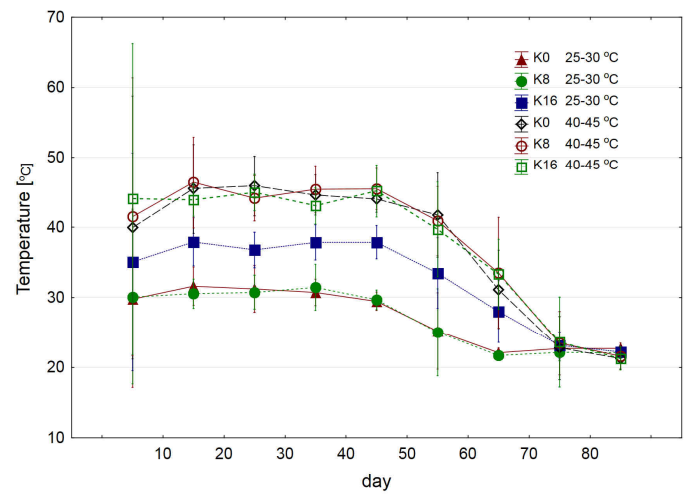

Fig. 4. Changes of the temperature of composted material during the period of 90 days (mean for 10 days $\pm S D)$

Mean temperature of composted materials during 10 and 50 days

\begin{tabular}{|c|c|c|c|c|}
\hline \multirow{2}{*}{ Object } & \multicolumn{2}{|c|}{$\mathbf{0 - 1 0}$ days $(\boldsymbol{n = 1 4 4 0 )}$} & \multicolumn{2}{c|}{$\mathbf{0 - 5 0}$ days $\left(\boldsymbol{n}=\mathbf{7 2 0 0}^{\mathbf{2}}\right)$} \\
\cline { 2 - 5 } & $\mathbf{2 5 - 3 0} \mathbf{C}$ & $\mathbf{4 0 - 4 5}^{\circ} \mathbf{C}$ & $\mathbf{2 5 - 3 0}^{\mathbf{C}} \mathbf{C}$ & $\mathbf{4 0 - 4 5}^{\mathbf{C}} \mathbf{C}$ \\
\hline K0 & $31.7 \pm 2.7^{*}$ & $43.2 \pm 2.1$ & $30.6 \pm 3.1$ & $43.9 \pm 5.0$ \\
\hline K8 & $32.0 \pm 2.2$ & $44.8 \pm 2.2$ & $30.5 \pm 3.0$ & $44.5 \pm 5.1$ \\
\hline K16 & $37.6 \pm 2.0$ & $47.4 \pm 4.0$ & $37.1 \pm 3.8$ & $44.2 \pm 5.2$ \\
\hline
\end{tabular}

$* \pm S D$

Over the period of 50 days, the temperature in other objects did not differ within the standard deviation (7270 measurements) in different temperatures. It confirms the fact, that the process activity depended in the first place on the temperature and not on the nonwoven 
fabric share in the plant material. However, in the case of lower temperature a bigger share of nonwoven fabric was important. It probably caused bigger porosity of the mixture which favoured microorganism development. It was confirmed by the results of mean temperature over the period of 10 days. In the K16 object, the mean temperature within the $40-45^{\circ} \mathrm{C}$ range was higher than the programmed upper range limit. It might result from intensive microbial processes occurring in the composted mixture.
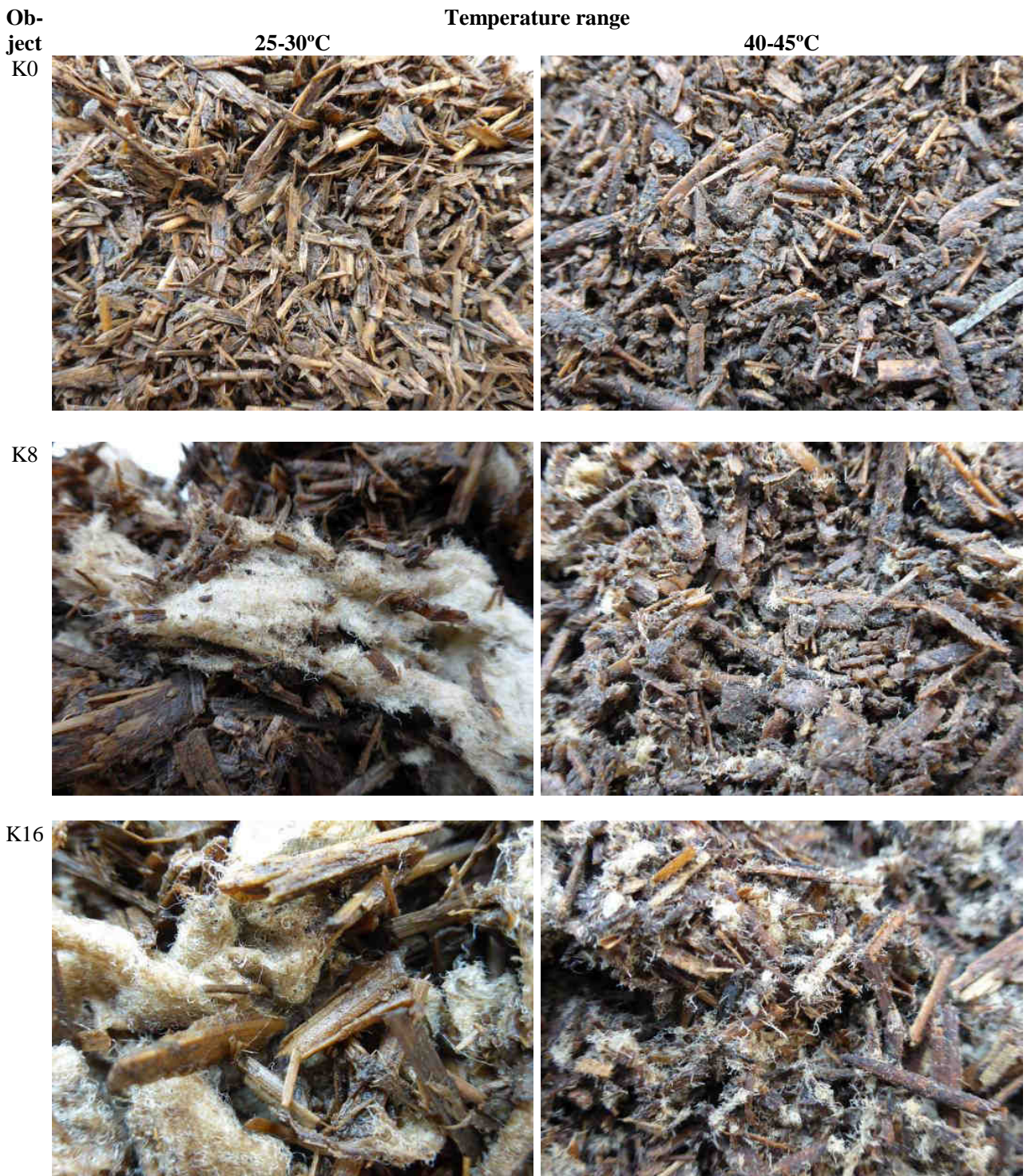

Fig. 5. Materials after 90-day composting in two ranges of temperature 
In the organoleptic evaluation, the composted material differed considerably among the objects (Figs. 5 and 6). Nonwoven fabric pieces measuring $10 \mathrm{~cm} \mathrm{x} 10 \mathrm{~cm}$ were degraded in all objects (K8 and K16), however for the lower range of ambient temperatures, nonwoven parts much bigger than $1 \mathrm{~cm}^{2}$ were found. In the case of the $40-45^{\circ} \mathrm{C}$ range, single fibres about 10 millimetres long were found, whereas numerous tangled fibres were noted in the treatment with a $16 \%$ addition.

Biodegradation of material during composting must occur in moist environment. The first stage of degradation is hydrolysis and it most probably also depends on vapour pressure. The pressure of saturated vapour was twice as high at the temperature of $30^{\circ} \mathrm{C}$ $(42.4 \mathrm{hPa})$ than at the temperature of $45^{\circ} \mathrm{C}(95.7 \mathrm{hPa})$. It is undoubtedly the reason, why copolyesters are easily broken into smaller fragments, susceptible to microbial and enzymatic breakdown. The proper course of composting depends on the material porosity and its structure. The air more saturated with vapour favours copolyester breakdown. Song et al [13] claim that, based on the analyses of BTA (aliphatic-aromatic copolyester of terephthalate adypine acid and 1,4-butylene), partially broken down at 35 and $75^{\circ} \mathrm{C}$, the temperature affects the degree, but not the character of degradation. However, the extent of disintegration is also important, because it facilitates mechanical crushing when mixing the compost prism.

a)

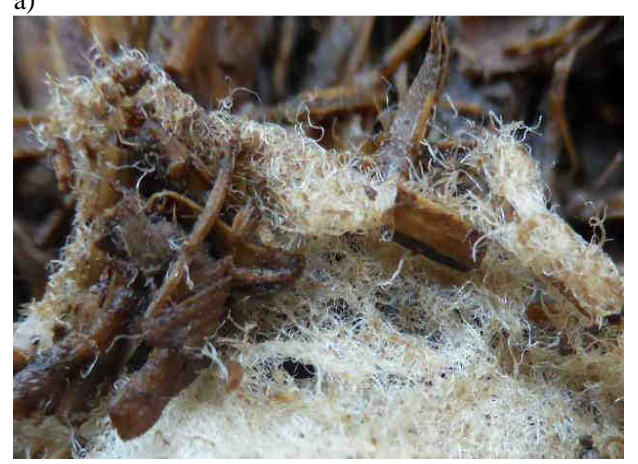

b)

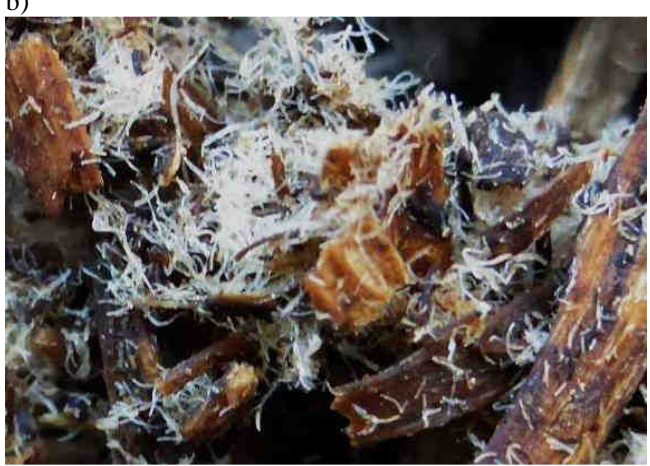

Fig. 6. A close-up of materials composted with $16 \%$ share of nonwoven fabric at $25-30^{\circ} \mathrm{C}$ (a) and $40-45^{\circ} \mathrm{C}$ (b)

\section{Biological activity}

The cumulated respiratory activity AT4 (Table 3) indicates the end of the process within the higher range of the temperatures. This value showed considerable diversification in the objects with nonwoven fabric addition at the lower temperature range.

Cumulated respiratory activity AT4 of composted materials $\left[\mathrm{mg} \mathrm{O}_{2} \cdot \mathrm{g}^{-1}\right.$ d.m.]

Table 3

\begin{tabular}{|c|c|c|}
\hline \multirow{2}{*}{ Object } & \multicolumn{2}{|c|}{ Temperature range } \\
\cline { 2 - 3 } & $\mathbf{2 5 - 3 0} \mathbf{C}$ & $\mathbf{4 0 - 4 5}^{\circ} \mathbf{C}$ \\
\hline K0 & 18.69 & 1.24 \\
\hline K8 & 12.76 & 5.61 \\
\hline K16 & 6.60 & 2.29 \\
\hline
\end{tabular}

Measurement error $=0.04 \mathrm{mg} \mathrm{O} \cdot \mathrm{g}^{-1} \mathrm{~d} \cdot \mathrm{m}$. 
The limit AT4 value was elaborated for the stabilisers of municipal wastes (10 $\mathrm{mg} \mathrm{O}_{2} \cdot \mathrm{g}^{-1}$ d.m.). It is believed, that material characterised by its activity below this limit is biologically stabile. This value can be treated a reference point for other biologically transformed materials (composting). Lower final respiratory activity might have been caused by a bigger material porosity, which resulted in biological changes during the process. Aerial porosity of the material caused by the added nonwoven fabric, most probably favoured the optimal oxygen supply to the bed in the reactor. It also let to an increase and stabilisation of the temperature (object $\mathrm{K} 1620-30^{\circ} \mathrm{C}$ ) and allowed to reach the stability of the composted material faster. Under laboratory conditions, Bobek at al [14] found, that the availability of polymers to microorganisms also depends on the surface and a kind of polymer, eg BTA foil > BTA nylon line > PDLLA > PLLA. Degradation of polyesters may be accelerated through forming mixtures with other biodegradable materials and therefore facilitating microorganism settling of biodegradable polymers which are hard to degrade. Ozimek and Kopec [15] confirmed, that adding biodegradable wastes to composted biomass significantly influences the dynamics of changes in the composting process.

\section{Humic compounds}

As a result of composting, the material with diversified carbon contents was obtained (Table 4). The analysis of organic matter fractional composition revealed relatively small diversification in the content of extracted carbon. The highest contents were noted in composts without nonwoven fabric supplement (K0), maintained at both temperatures. With increasing nonwoven share in the composted biomass, the extracted $\mathrm{C}$ content was decreasing. Copolyesters were diluting organic carbon in the biomass, but its higher contents in the objects with the $40-45^{\circ} \mathrm{C}$ temperature range testify the incorporation of copolyester carbon in the processes of microorganism metabolism.

Table 4

Content of carbon $\left[\mathrm{g} \mathrm{C} \cdot \mathrm{kg}^{-1} \mathrm{~d}\right.$.m.] of individual organic matter fractions of composted materials

\begin{tabular}{|c|c|c|}
\hline \multirow{2}{*}{ Object } & \multicolumn{3}{|c|}{ Temperature range } \\
\cline { 2 - 3 } & \multicolumn{2}{|c|}{ C extract } \\
\hline K0 & $124.2 \pm 1.4^{*}$ & $\mathbf{4 0 - 4 5}^{\circ} \mathbf{C}$ \\
\hline K8 & $66.4 \pm 5.4$ & $95.8 \pm 2.7$ \\
\hline K16 & $44.1 \pm 2.2$ & $78.6 \pm 7.1$ \\
\hline K0 & $65.4 \pm 4.3$ & $72.2 \pm 3.8$ \\
\hline K8 & $35.6 \pm 6.5$ & $64 \pm 11$ \\
\hline K16 & $25.1 \pm 2.1$ & $41.4 \pm 3.3$ \\
\hline K0 & $59.8 \pm 2.9$ & $44 \pm 12$ \\
\hline K8 & $31.4 \pm 5.9$ & $\boldsymbol{C}_{f a}$ \\
\hline K16 & $19.6 \pm 2.2$ & $32.1 \pm 6.7$ \\
\hline K0 & $381.1 \pm 1.2$ & $28.3 \pm 7.7$ \\
\hline K8 & $482.6 \pm 4.4$ & $406.1 \pm 2.6$ \\
\hline K16 & $521.4 \pm 2.0$ & $445.2 \pm 4.0$ \\
\hline
\end{tabular}


Similar dependencies, reffered also to humic acid carbon. The highest $C_{h a}$ concentrations were assessed in alkaline extracts obtained from composts without nonwoven fabric supplement (K0). On the other hand, Richter et al [16] report enzymatic character of BTA degradation with a small share of hydrolysis processes and the fact that the higher the share of aromatic rings, the more difficult the microbial decomposition [4].

The content of fulvic acid carbon was lower in each of the investigated objects than $\mathrm{C}$ content in humic acid fractions. The least amounts of $C_{f a}$ were assessed in composts in which nonwoven fabric supplement was the highest (K16), irrespective of the ambient temperature. The content of non-hydrolysing carbon, except the composts without nonwoven fabric addition (K0) was the lowest in materials maintained at the temperature of $40-45^{\circ} \mathrm{C}$.

A supplement of biodegradable material to the composted biomass led to a diversification of $C_{h a}: C_{f a}$ ratio value (Table 5). Values of $C_{h a}: C_{f a}$ ratio approximating 1.50 regarded as the optimum value were registered in $\mathrm{K} 16$ composts at the temperature of $40-45^{\circ} \mathrm{C}$. Values of the discussed parameter in $\mathrm{K} 0$ and $\mathrm{K} 8$ composts maintained at the temperature of $25-30^{\circ} \mathrm{C}$ indicate a slowdown of the biological degradation process. The value in $\mathrm{K} 0$ compost at $40-45^{\circ} \mathrm{C}$ shows that the mineralization process of the composted biomass was too advanced.

Absorbance coefficients of humic acid solutions did not reveal any major changes depending on nonwoven fabric supplement incorporated to the composting process (Table $5)$, whereas a greater diversification of this indices was related with the ambient temperature. Higher values of the absorbance ratio E4 : E6 refer to the composted materials kept at the temperature between 40 and $45^{\circ} \mathrm{C}$ to which biodegradable polymer materials were added. It may indicate a considerable decrease in the condensation degree of humic acid particles or greater aliphatisation and a higher number of functional groups. At earlier stages of their formation, humic acids of generally smaller molecular mass and lower degree of aromatic structure condensation are characterised by higher values of E4 : E6 ratio.

Values of humic acid carbon to fulvic acid carbon ratio and of absorbance determined at $456 \mathrm{~nm}$ (E4) and $665 \mathrm{~nm}$ (E6) wavelengths for the composted materials at $25-30^{\circ} \mathrm{C}$ and $40-45^{\circ} \mathrm{C}$

\begin{tabular}{|c|c|c|}
\hline \multirow{2}{*}{ Object } & \multicolumn{2}{|c|}{ Temperature range } \\
\hline & $25-30^{\circ} \mathrm{C}$ & $40-45^{\circ} \mathrm{C}$ \\
\hline & \multicolumn{2}{|c|}{$C_{h a}: C_{f a}$} \\
\hline K0 & 1.09 & 1.98 \\
\hline K8 & 1.13 & 1.10 \\
\hline \multirow[t]{2}{*}{ K16 } & 1.28 & 1,57 \\
\hline & \multicolumn{2}{|c|}{ E4 : E6 } \\
\hline K0 & 9.57 & 10.46 \\
\hline K8 & 9.40 & 10.47 \\
\hline K16 & 8.79 & 10.62 \\
\hline
\end{tabular}

Optic properties of humic acids may change not only as a result of mineralisation and humification of composted biomass. The type of organic matter used for the composting process, the quantity and kind of added polymer material also have an influence on these properties. It is important because the biodegradation process of some plastics is much faster in the "natural" environment than in simulated laboratory conditions [8] and it does 
not show an ecotoxic effect [16-18]. Humification process which occurred in the materials composted with a small amount of biodegradable materials is progressing similarly as humification process of organic matter supplied to the soil with organic fertilizers or other organic materials [19]. This fact was confirmed by the long-term research on polymer biodegradation carried out by Rudnik and Briassoulis [20].

\section{Conclusions}

1. Composting temperature effected the stability of plant materials composted with nonwoven fabric of aliphatic-aromatic copolyester poly(succinate-co-glutarateco-adipate-co-terephthalate 1,4-butylene) with addition of fatty acid dimmers.

2. An increase in the share of nonwoven fabric of copolyester in the compost caused a decrease in the share of carbon of humic and fulvic acids.

3. Material composted with the share of nonwoven fabric of copolyester is characterised by compounds of lower molar mass and lower degree of aromatic structure condensation. However, numerous functional groups present in this material, may be the cause of the formation of stabile humus compounds after its application to the soil.

\section{Acknowledgements}

The work was conducted within the project entitled "Application of biomass for producing environment friendly polymer materials" POIG 01.01.02-1-123/09, co-financed by the European Union funds in the framework of European Regional Development Fund Operational Programme Innovative Economy.

\section{References}

[1] Pałosz T. Rolnicze i środowiskowe znaczenie próchnicy glebowej i metodyka jej bilansu (Agricultural and environmental eignificance of soil humus and methods of its balance). Roczn Ochr Środ. 2009;11:329-338. http://ros.edu.pl/text/pp_2009_023.pdf.

[2] Witt U, Müller RJ, Deckwer WD. New biodegradable polyester-copolymers from commodity chemicals with favorable use properties. J Environ Polymer Degrad. 1995;3(4):215-223. http://link.springer.com/article/10.1007/BF02068676\#page-1.

[3] Briassoulis D, Hiskakis M, Scarascia G, Picuno P, Delgado C, Dejea C. Labeling scheme for agricultural plastic wastes in Europe. Quality Assurance and Safety of Crops and Foods. 2010:2(2):93-104. DOI: 10.1111/j.1757-837X.2010.00061.x.

[4] Tokiwa Y, Calabia BP, Ugwu ChU, Aiba S. Biodegradability of plastics. Int J Mol Sci. 2009;10:3722-3742. DOI: 10.3390/ijms10093722.

[5] Eubele JP. Biodegradation of Synthetic Polymers in the Aquatic Environment. Universitat Bremen, 2010: 209. http://elib.suub.uni-bremen.de/edocs/00101809-1.pdf.

[6] Musioł M, Rydz J, Sikorska W, Rychter P, Kowalczuk M. A preliminary study of the degradation of selected commercial packaging materials in compost and aqueous environments. Pol $\mathrm{J}$ Chem Technol. 2011;13(1):55-57. DOI:10.2478/v10026-011-0011-z.

[7] Dutkiewicz S, Wesołowski J, Chojnacki D, Ciechańska D. Method to produce biodegradable aliphatic-aromatic co-polyesters with improved colour. Fibres Text East Eur. 2012;20(6B):84-88. http://yadda.icm.edu.pl/baztech/element/bwmeta1.element.baztech-d24d821a-738b-40fe-8827a8d7a8f2b549.

[8] Chłopek J, Morawska-Chochół A, Szaraniec B. The influence of the environment on the degradation of polylactides and their composites. J Achiev Mater Manufac Eng. 2010;43(1):72-79. http://www.ww.journalamme.org/papers_vol43_1/4315.pdf.

[9] Kondratowicz FŁ. Ukielski, R. Synthesis and hydrolytic degradation of poly(ethylene succinate) and poly(ethylene terephthalate) copolymers. Polymer Degrad Stab. 2009;94(3):375-382. DOI: 10.1016/j.polymdegradstab.2008.12.001. 
[10] ISO 14855-1:2005, Determination of the Ultimate Aerobic Biodegradability of Plastic Materials Under Controlled Composting Conditions - Method by Analysis of Evolved Carbon Dioxide - Part 1: General Method, Edition. http://www.iso.org/iso/iso_catalogue/catalogue_tc/catalogue_detail.htm?csnumber=57902.

[11] Sadaka SS, Richard TL, Loecke TD, Liebman M. Determination of compost respiration rates using pressure sensors. Compost Sci Util. 2006:14(2):124-131. DOI: 10.1080/1065657X.2006.10702273.

[12] Griffith SM, Schnitzer M. A study in the infrared of high-molecular weight organic matter extracted by various reagents from a podzolic B horizon. Soil Sci Soc Am Proc. 1975;39:861-867. DOI: 10.1097/00010694-195905000-00003.

[13] Song J, Šišková A, Simons MG, Kowalski WJ, Kowalczuk MM, van den Brink OF. LC-multistage mass spectrometry for the characterization of poly(butylene adipate-co-butylene terephthalate) copolyester. J Am Soc Mass Spectrom. 2011;22:641-648. DOI:10.1007/s13361-010-0071-y.

[14] Bobek B, Smyłł A, Rychter P, Biczak R, Kowalczuk M. Microbial degradation of selected polyesters in soil. Proc ECOpole. 2009;3(1):51-57. http://tchie.uni.opole.pl/ecoproc09a/BobekSmylla_PECO09_1.pdf.

[15] Ozimek A, Kopeć M. Ocena aktywności biologicznej biomasy na różnych etapach procesu kompostowania przy użyciu systemu pomiarowego Oxi Top Control. (Assessment of biological activity of biomass at different stages of composting process with use of the Oxi Top Control measurement system). Acta Agrophys. 2012;19(2):379-390. http://www.acta-agrophysica.org/pl/artykul/64

[16] Rychter P, Kawalec M, Sobota M, Kurcok P, Kowalczuk M. Study of aliphatic-aromatic copolyester degradation in sandy soil and its ecotoxicological impact. Biomacromolecules. 2010;11(4):839-847. DOI: $10.1021 / \mathrm{bm} 901331 \mathrm{t}$.

[17] Herman B, Biczak R, Rychter P, Kowalczuk M. Degradation of selected synthetic polyesters in the industrial compost heap: effect on compost properties and phytotoxicity. Proc ECOpole. 2010;4(1):133-140. http://tchie.uni.opole.pl/ecoproc10a/HermanBiczak_PECO10_1.pdf.

[18] Nowak B, Pająk J. Biodegradation of polylactide (PLA). Archiv Waste Manage Environ Prot. 2010;12(2):1-10. http://awmep.org/?journal=ago\&page=article\&op=view\&path[]=131

[19] Gondek K, Mierzwa M. Quantity and quality of organic matter in soil after application of various organic materials. Ecol Chem Eng S. 2014;21(3):477-485. DOI: 10.2478/eces-2014-0035.

[20] Rudnik E, Briassoulis D. Comparative biodegradation in soil behaviour of two biodegradable polymers based on renewable resources. J Polymers Environ. 2011;19(1):18-39. DOI: 10.1007/s10924-010-0243-7. 